Proceedings

\title{
Is an Animal Welfare Label Enough? Role of Farm Animal Welfare Voluntary Labelling Schemes in the Development of Sustainable Livestock Production ${ }^{\dagger}$
}

\author{
Justyna Zwolińska * and Sylwia Żakowska-Biemans
}

Citation: Zwolińska, J.; ŻakowskaBiemans, S. Is an Animal Welfare

Label Enough? Role of Farm Animal Welfare Voluntary Labelling Schemes in the Development of Sustainable Livestock Production. Proceedings 2021, 73, 8.

https://doi.org/10.3390/ IECA2020-08831

Published: 2 December 2020

Publisher's Note: MDPI stays neutral with regard to jurisdictional claims in published maps and institutional affiliations.

Copyright: $@ 2020$ by the authors. Licensee MDPI, Basel, Switzerland. This article is an open access article distributed under the terms and conditions of the Creative Commons Attribution (CC BY) license (http://creativecommons.org/licenses/by/4.0/).

\author{
Department of Food Market and Consumer Research, Institute of Human Nutrition Sciences, \\ Warsaw University of Life Sciences (SGGW-WULS), 02-776 Warsaw, Poland; \\ sylwia_zakowska_biemans@sggw.edu.pl \\ * Correspondence: justyna_zwolinska@sggw.edu.pl \\ † Presented at the 1st International Electronic Conference on Animals-Global Sustainability and Animals: \\ Science, Ethics and Policy, 5-20 December 2020; Available online: https://ieca2020.sciforum.net/.
}

\begin{abstract}
Intensive livestock production devoid of elementary foundations for the welfare of farm animals is nowadays identified as one of the main factors contributing to the growing environmental and social threats. Public opinion associates the welfare of farm animals with values relating to health, food quality, ethical approach to animals and protection of the environment and climate. Accordingly, the social conceptualization of farm animal welfare plays an important role in guiding EU policy and developing animal welfare law. It also becomes a prerequisite for solving social and environmental problems resulting from intensive animal production. Farm animal welfare is an intangible and credence attribute of food and as such requires a means of informing consumers about it. The most preferred form of communication about the welfare level of farm animals among consumers are farm animal welfare labels. Both consumer preferences and their expectations of how farm animal welfare is communicated are reflected in the development of public and private food labelling systems in the European Union. Therefore, the main aim of the study was to analyse the selected farm animal welfare voluntary labelling schemes in terms of their potential for the development of sustainable animal production in the EU. The result of the study shows the differences and similarities in this respect between public and private systems, in relation to four criteriavalues associated by consumers with the welfare of farm animals - health, food quality, ethics and environmental protection. We provide an overview of these systems and their role in increasing farm animal welfare standards. We conclude that it is particularly important to verify if the shift from production-related concern to social and consumer-related concern can constitute a sufficient and effective form for a systemic change transforming current animal production into production based on higher livestock welfare standards.
\end{abstract}

Keywords: animal welfare; labelling schemes; communication; consumers; sustainable agriculture

\section{Introduction}

"There is an increasing appreciation of animal welfare parameters over other quality attributes, and animal-friendly products are considered healthier, safer, tastier, more hygienic, authentic, environmentally friendly, and traditional by many consumers" [1]. It is also one of the factors contributing to the inclusion of farm animal welfare in the process of defining sustainable agriculture both as "a threat to sustainability and as vectors for delivering sustainability" [2]. The role of farm animal welfare improvement in the development of sustainable agricultural for food security and nutrition was highlighted in recommendation drafted by the United Nations Committee on World Food Security and was 
many times indicated by the Organization for Animal Health (OIE) and the Food and Agriculture Organization of the United Nations (FAO).

Therefore, combining these two phenomena-the constantly growing interest of the public opinion about the farm animal welfare and its recognition in the political and legal processes for the development of sustainable agriculture at the level of the international and EU law systems - it is necessary to analyse which instruments to the greatest extent meet both consumer expectations towards farm animal welfare standards and potentially the largest contribution in transforming current livestock production to be more sustainable.

The main solution that has been considered and developed in the European Union for at least 15 years is focusing on the replacement of the further development of farm animal legislation by supporting market-driven initiatives [3] based on and combined with appropriate consumer-oriented communication about farm animal welfare as intangible and credence attribute of food. Increasingly, the introduction of the EU farm animal welfare label is being considered as a harmonized basis for development of "animal welfare labelling scheme as a certification system that certifies an animal welfare standard above existing legal standards". The main goal is "enabling consumers to make informed purchasing decisions" as having potential "to give an economic incentive to industry to improve the welfare of animals" [4].

If consumers' perception of animal welfare is to be the main force in shifting EU livestock production towards "a fair, healthy and environmentally friendly food system" [5], the role of existing voluntary food labelling schemes in the EU should be analysed in terms of how they communicate the values that consumers associate with animal welfare, i.e., health, food quality, ethical approach to animals and protection of the environment and climate. The main objective of the study was therefore to review selected voluntary farm animal welfare labelling schemes in terms of their potential for the development of sustainable livestock production in the EU.

\section{Material and Methods}

Associations of consumers with the welfare of farm animals were grouped into four values based on a literature review, Eurobarometer survey results and own research in this area. They were then referenced to the six food labelling schemes depending on whether they focus:

- $\quad$ only on animal welfare;

- $\quad$ on various aspects including animal welfare;

- on aspects other than animal welfare but have positive side effects on animal welfare.

Following this division, the Bedre Dyrevelærd, Beter Leven systems, and the Etiquette Bien-être animal were discussed as an example of the first scheme. An example of the second scheme is the Label Rouge. Additionally, one of the Polish food quality systems, Quality Meat Program (QMP), was reviewed.

An additional criterion for the selection of these systems-in order to diversify the systems in question as much as possible-involved their characteristics regarding the main promoter and the way of establishing a given system, the duration of the system operation in the EU and the species of farm animals covered by the system.

Accordingly, the review concerns:

- three private systems - Beter Leven, Bien-Être and the Quality Meat Program (QMP), whose establishment promoters were non-governmental organizations in cooperation with partners across the food chain and/or business.

- two national systems, created by the governments-Bedre Dyyrevelærd and Label Rouge.

The oldest is the Label Rouge system, established in 1965. Beter Leven label was introduced in 2007. Quality Meat Program (QMP) was recognized in 2008 by the Polish Minister of Agriculture and Rural Development as the national food quality system. The 
newest systems are Bedre Dyrevelærd established in 2017 and Bien-Être, which introduced the first animal welfare label in France in 2018.

The Label Rouge system covers all livestock species. Second in terms of number of species is Beter Leven, including pigs, broilers, chickens, laying hens, beef cattle, claves, rabbits, dairy cows and turkey. Then, Bedre Dyrevelærd for pigs, broilers, calves. The animals at Bien-Être include broilers and, by 2021, pigs. QMP is only for beef cattle.

To evaluate the communication content of individual system, a review of the information available on the official website of a given system was carried out, including verification of its criteria.

\section{Results}

\subsection{Communicating about Health, Food Quality, and Environmental and Climate Protection}

Private voluntary farm animal welfare labelling systems refer in a limited way to information about health, food quality, environmental and climate protection. Exclusively, the Beter Leven system states that the prophylactic use of antibiotics and hormones in animals is prohibited. It is also the only system that emphasizes the relationship of animal welfare to environmental and climate values by communicating about the greatest possible use of local feed and stimulation of local forage sourcing as feed imports from outside the EU contribute to deforestation and environmental pollution worldwide. The communication about Beter Leven system also highlights: the use of pesticides with low environmental impact, the use of manure to fertilize the land as well as the obligation of farmers to keep a record of the use of mineral fertilizers and their balanced use. In this system, attention is also focused on the preservation of biodiversity in meadows and wetlands as places friendly to insects and birds, including protected species. At least $5 \%$ of the meadows should be managed extensively. One of the goals is also to encourage the system's stakeholders to use green energy and achieve climate neutrality by 1 January 2030. The public, Danish Bedre Dyrevelærd system, mentions feed of the right quality and quantity. However, this information is so enigmatic that it can be interpreted both as recommendations for animal nutrition or in relation to the source of feed. This is similar to the information provided by another public system, the Label Rouge system, which gives very detailed information on the composition of poultry feed. The Label Rouge emphasizes traditional agricultural practices, especially the maintenance of local breeds, which in communicating about the system is associated with sustainable agriculture. It is noteworthy that only Label Rouge uses the concept of "sustainable agriculture" in its official informing about the system. The most information in this system concerns food quality, as the main message is to emphasize that Label Rouge poultry has a better taste than standard poultry. The confirmation that Label Rouge poultry has superior organoleptic properties than standard poultry is the comparison of their flavour by experts and consumer panels during the annual blind test. It should be emphasized, however, that there is a direct link to animal welfare in the Label Rouge poultry system, as information is provided on increased area in poultryhouse, maintenance of "free-range or in total freedom", as well as the choice of slow-growing hardy breeds and life span extension of animal over 81 days.

This is a fundamental difference between Label Rouge and the Polish Quality Meat Program (QMP) system, which refers in the information provided to the qualities of meat-its guaranteed high-quality, higher culinary quality of beef, and defining it with adjectives "tasty, tender, juicy and soft". The QMP standards relate to transport-however, only in accordance with the provisions of the EU law on the transport of farm animal - and cattle feeding standards only in relation to the administration of fish oil in relation to the EU law on BSE carry-over hazards. There is no relationship between high-quality beef and cattle welfare in communicating about QMP. This program also makes no reference to the values of health and environmental and climate protection. 


\subsection{Communicating about an Ethical Approach to Animals}

With the exception of the QMO Program previously mentioned, all private animal product labelling systems and the Danish public system focus the most on communicating animal welfare. It should be noted that each of these systems introduces a gradation of farm animal welfare standards. In the case of Bedre Dyrevelærd and Beter Leven, this is a three-tier system in which the more hearts or stars, the greater the animal welfare. In the case of the Etiquette Bien-Être animal system, the gradation is five-stage (from A to E), where the highest welfare it is marked with the letter A.

In communication about these systems, words such as ethical or humanitarian husbandry do not appear. The message to consumers is built on indication of the specific conditions of the animal's life, i.e., increasing the area per animal in buildings, the possibility of going outside or grazing, access to fresh air, daylight and maintaining the natural day/night cycle as well as to provide the animals with greater comfort especially in the form of improved floor space and the ability to lie down (straw bedding). Communication also concerns an enriched environment, so that individual species of livestock can meet their natural needs. Other aspects of animal welfare communicated by these food labelling systems are also: extending the time the calves remain with their mothers, the slower grow rate, and the shortening of the transport time of the animals.

On the other hand, the communication content of the Beter Leven system includes information about the stunning of animals before ritual slaughter, "tails are cut in pigs but the tail remains longer than in traditional pig production", and about the "removal of horns in cattle, admittedly by a vet and with the administration of anesthesia and pain relief. Castration of bulls is also allowed as an alternative to keeping them indoors. Likewise, information on the Bedre Dyrevelærd system contains limited approval for the use of farrowing pens for sows. It should also be emphasized that Label Rouge is approved for fois gras, i.e., products derived from force-fed animals.

\section{Discussion}

The review is an introduction to an in-depth analysis of the relationship between voluntary farm animal welfare labelling systems and communicating them to consumers, and their potential impact on the development of sustainable agriculture or the wider sustainable food chain in the EU. For the purposes of the article, it was limited to the verification of official websites of the food labelling schemes in search for the scope of information on farm animal welfare that consumers associate with four values relating to health, food quality, ethical approach to animals and environmental and climate protection. This is particularly worrying given the data in the IPES Food Report [6] on the effects of intensive livestock production on human health, the environment and climate, as well as Europeans' concern about the increase in antibiotic resistance due to the widespread administration of antibiotics in intensive livestock production [7].

The results of the review indicate the expansion of communication regarding the conditions of husbandry and transportation of farm animals. On the other hand, the relationship between the welfare of farm animals and aspects relating to health, food quality, and especially environmental and climate protection is of little importance and is rather an exception. Another issue is the release of information on the mutilation or castration of farm animals, which may raise consumer doubts regarding the welfare standards adopted under a given farm animal welfare labelling scheme. Moreover, communication on the welfare of farm animals is often based on comparing the improved welfare standards with the minimum standards mandated by EU law. It should therefore be taken into account that consumer awareness of animal protection and welfare legislation is still low and fragmented. Perhaps consideration should be given to integrating more information into communication of farm animal welfare regarding the importance of improving their health and behaviour as well as demonstrating their level of intelligence, emotionality and ability to create social relationships - instead of using minimum standards as a point of reference 
from which farm animal welfare standards are raised. The gradation of farm animal welfare labels should also be considered as some communication difficulties for consumers. Rather, the main purpose of staging improvements in the welfare of farm animals is to facilitate the accession of producers to animal welfare systems.

Consumers are not just recipients of information-especially in the European Union, public opinion should rather be perceived as a driving force for change for the constant improvement of animal welfare, to which both public authorities and the private sector respond. For this reason, actors of livestock welfare change should consider the scope of communication on the farm animal welfare label and the system behind it as a field of common reflection on how to incorporate more and more new elements of improving farm animal welfare in relation to sustainable agriculture.

Taking into consideration the differences between the voluntary food labelling systems of animal origin, it should be recognized that there are major disproportions in their impact on the sustainability of EU agriculture. It may even be considered a risk factor for the further progress of sustainable agriculture. However, combining them and perceiving them more as a social and economic movement towards sustainable animal production, it must be recognized that they are initiatives with enormous potential for change. In this context, it should also be considered whether the multiplication of voluntary farm animal welfare labelling systems - often by system creators related to the requirements of organic production - should not be replaced by directing support to the greatest possible development of organic farming, which ex definitione combines all elements of sustainable agriculture, including high welfare of farm animals; especially that the public debate on the methods and practices of agricultural production (agroforestry, holistic pasture, rotation grazing) with the use of farm animal welfare, which can effectively contribute to both mitigation of climate change and protection of natural resources, has been developing dynamically in recent years.

Data Availability Statement: Not applicable.

Conflicts of Interest: The authors declare no conflict of interest.

\section{References}

1. Alonso, M.E.; González-Montaña, J.R.; Lomillos, J.M. Consumers' concerns and perceptions of farm animal welfare. Animals 2020, 10, 1-13.

2. Miele, M.; Lever, J. Improving animal welfare in Europe: Cases of comparative bio-sustainabilities. In Sustainable Food Systems: Building a New Paradigm; Routledge: Abingdon, UK, 2014; pp. 143-165.

3. Sandøe, B.P.; Christensen, T. Farm Animal Welfare in Europe: From Legislation to Labelling. Available online: https://animalethics.ku.dk/research-files/From_legislation_to_labelling.pdf (accessed on 10 November 2020).

4. European Commission Directorate General for Health and Consumer Protection. Civic Consulting Feasibility study on animal welfare labelling and establishing a Community Reference Centre for Animal Protection and Welfare Part 1: Animal Welfare Labelling. Available online: http://www.civic-consulting.de/reports/aw_labelling_study_part1.pdf (accessed on 10 October 2020).

5. Communication from The Commission to the European Parliament. The Council, The European Economic and Social Committee and the Committee of the Regions. A Farm to Fork Strategy for a Fair, Healthy and Environmentally-Friendly Food System. Available online: https://eur-lex.europa.eu/legal-content/EN/TXT/PDF/?uri=CELEX:52020DC0381\&from=EN (accessed on 10 October 2020).

6. IPES-Food Panel towards a Common Food Policy for the European Union. The policy reform and realignment that is required to build sustainable food systems in Europe. 2019, 42-51 Available online: www.ipes-food.org/pages/\%0ACommonFoodPolicy (accessed on 10 October 2020).

7. Special Eurobarometer 445: Antimicrobial Resistance. Available online: https://data.europa.eu/euodp/fi/data/dataset/S2107_85_ 1_445_ENG (accessed on 10 October 2020). 